\title{
Research on Adhesive Joints of Low-temperature composite Axial Insulation Break \\ Changchun Yang
}

College of Electric Engineering, Jiujiang University, China 332005

395254993@qq.com

Keywords: Adhesive joint, Insulation Break (IB), Insulation process, Low-temperature

Abstract. Threaded adhesive joints between stainless steel electrodes and insulating structure of axial insulation break was studied in detail. Wet winding process was chosen for Glass Fiber Reinforced Plastic inner insulation tube, and threaded adhesive method was chosen for joints bonding GRP to Stainless Steel. DC High voltage test showed that it is fairly good results to eliminate the interface crack in low temperature heat shrinkage and mechanical stress to meet $56 \mathrm{kV}$ insulation requirements for superconducting magnetic systems.

\section{Introduction}

Low-temperature high-voltage Helium tightness composite axial insulation breaks are key components of superconducting magnet systems [1]. Axial electrical insulation breaks are required to provide isolation between the cryogenic pipe-line potential and the coil potential. According to experience, if the mechanical properties are complete, then the electrical properties will be maintained. Therefore, low temperature and room temperature mechanical properties are well-proven cases; the proposed high voltage test can be conducted only at room temperature [2].

This length ensures a dielectric strength along the inner pipe interface between high voltage and low voltage parts. DC High voltage test for the insulation breaks prototype, test design should be provided to meet the specified design voltage $29 \mathrm{kV}, 35 \mathrm{kV}$ and $56 \mathrm{kV}$, the design of these tests can also determine the scope of the breakdown field strength.

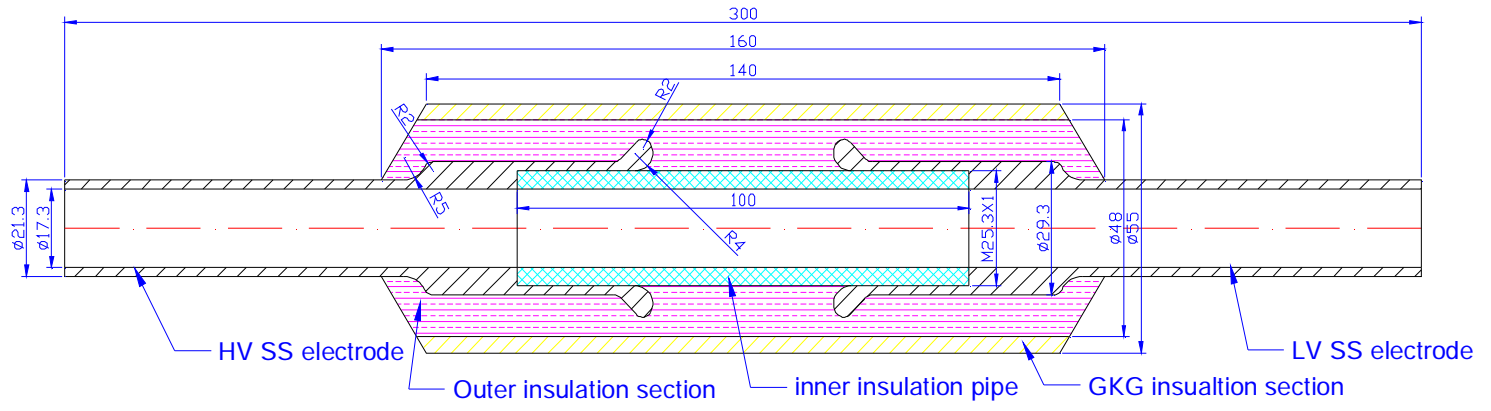

Fig. 1.The cross-section of the final design axial insulation break

The design of ITER axial insulation breaks are showed in Fig.1. The breaks consist essentially of an insulated tube between the two steel tubes inserted into the steel cryogenic line. The outer surface has a metal screen which is integrated into the ground screen of the high voltage cryogenic line, and there is metal reinforcing of both the insulating part, particularly where it overlaps the steel tubes to form a bond [3]. There length must be sufficient to prevent electrical breakdown between the two steel tubes through the fluid or gas. 


\section{Stainless Steel electrodes}

Stainless steel AISI 316L is chosen as two end electrodes materials of ITER composite axial IB.AISI 316L is an austenitic stainless steel with superior corrosion resistance, and it has extensive application at cryogenic temperatures. The chemical composition range is quite large and may need restricting to achieve the required mechanical properties. The low carbon content reduces susceptibility to carbide precipitation during welding. The design of SS pipe electrode is showed in Fig.2.

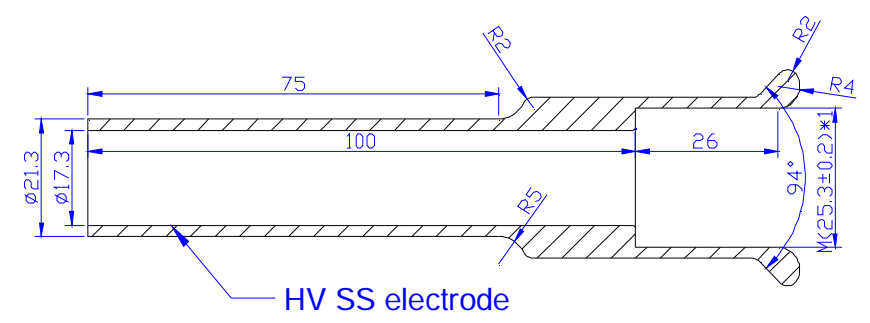

Fig.2.The design of SS pipe electrode

\section{Insulation structure}

Glass fiber reinforced epoxy resin composite is chosen as insulation structure materials and two end electrodes materials of ITER composite axial IB.

DWZ cryogenic epoxy resin. DWZ cryogenic epoxy resin system is chosen for insulation structure adhesive that is EAST patent. This type of epoxy resin system is composed of two components, one is DGEBA epoxy resin, the other is curing agent that is a mixture of GY051 and DDM. The percentage of these two components in weight is $4: 1$ in which the curing agent is 1 unit.

Glass-Fiber. $\mathrm{R}$ glass fibers are chosen as the strengthening material according to last test. Glass fiber filament R-glass is stored in a drier. Tex of glass tow is 500 .

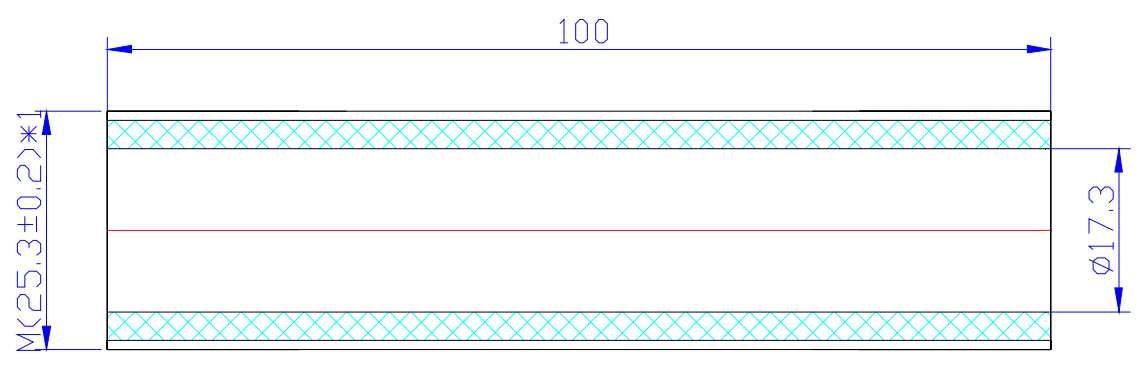

Fig.3 The design of GFRP inner insulation pipe

Glass Fiber Reinforced Plastic (GFRP) inner insulation tube. The design of GFRP inner insulation pipe is showed in Fig.3. Wet winding process method was chosen. $\mathrm{R}$ glass tows are winded wet with DWZ resin on mold by hand after the mold is half lapped with Teflon tape as non-stick and slide materials. The mold was fixed on the winding machine. The fiber winding angle is about $30^{\circ}$ to radial direction. Tow tex is 500 , tension is $2 \mathrm{~kg}$ and fiber speed is less than $6 \mathrm{~mm}$ per second. At last, the silicone tapes are wrapped on the outer of inner tube to keep DWZ not flow out.

\section{Threaded adhesive joints bonding GRP to Stainless Steel}

It is important that the contraction to low temperature on the outside diameter of the inner GRP tube 
should be less than the contraction of stainless steel to eliminate tensile strain in the bond. Bonding insulation tube to stainless tube using DWZ cryogenic resin was chosen as the method. The GRP contraction will be determined by the fiber content and winding angle and it is important these variables are controlled so that the bond is in compression at $4 \mathrm{~K}$.

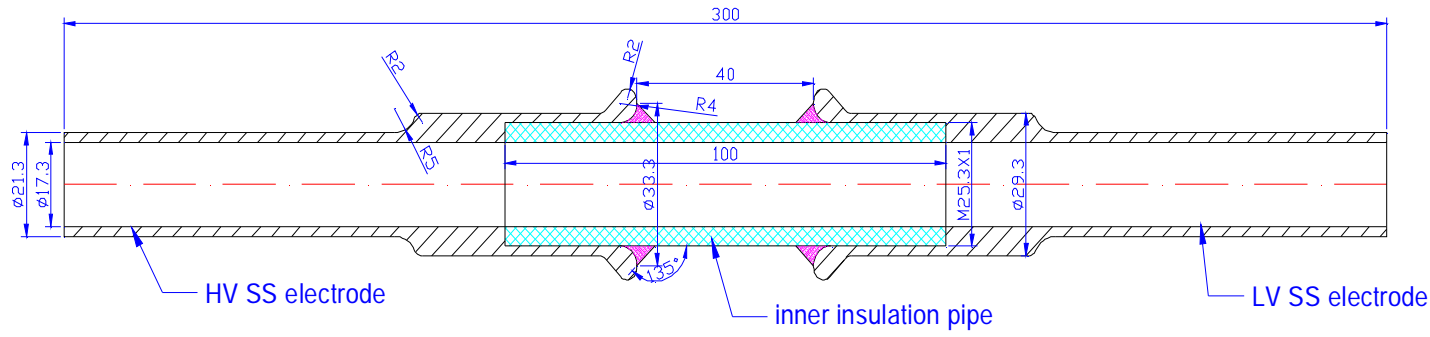

Fig.4 Threaded adhesive joints bonding insulation tube to stainless tube

Glass tow will be winded around the stainless steel end fittings. It is ensured that the glass will be uniform in all areas and there are no resin rich areas or areas of high glass content. Threaded adhesive joints bonding insulation tube to stainless tube are showed in Fig.4.

Process in detail is as follows: 1) Glue resin on bonding surface; 2) Rotate the inner tube into the electrodes by the thread; 3) Rotate back 2 circle and put glass tow into fitting area to keep no rich resin; 4) Rotate the inner tube into the electrodes and bond; 5) Cure under DWZ resin cure schedule

After preliminary test, the outer strengthening insulation structure will be fabricated by using the wet winding method.

\section{Test}

Withstanding voltage level testing device of ITER insulation break component was shown in Figure 5, insulation level test results in side-by-side shown in Figure 6. According to requirements to ground insulation, the insulation resistance must be more than $1 \mathrm{G} \Omega$, so the leakage current of the $35 \mathrm{kV}$ voltage levels should be less than $35 \mu \mathrm{A}[4]$. We see from Figure 6, when high voltage $56 \mathrm{kV}$ for 1 minute for insulation break side-by-side, the leakage current is less than $1.5 \mu \mathrm{A}$ to fully meet the requirements. Because in the practical application the outside of insulation break have also a certain thickness of the insulating layer winding, insulation in bulk can also meet the ITER requirements. After the fatigue testing, the electrical performance of insulation break is sufficient[5].

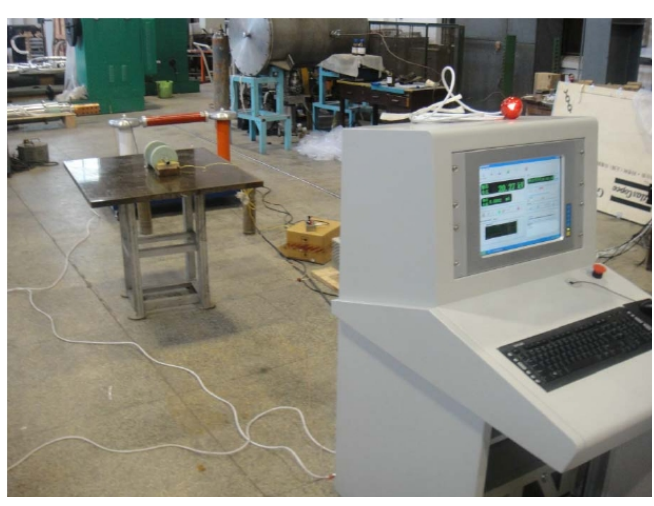

Fig.5 test equipment components

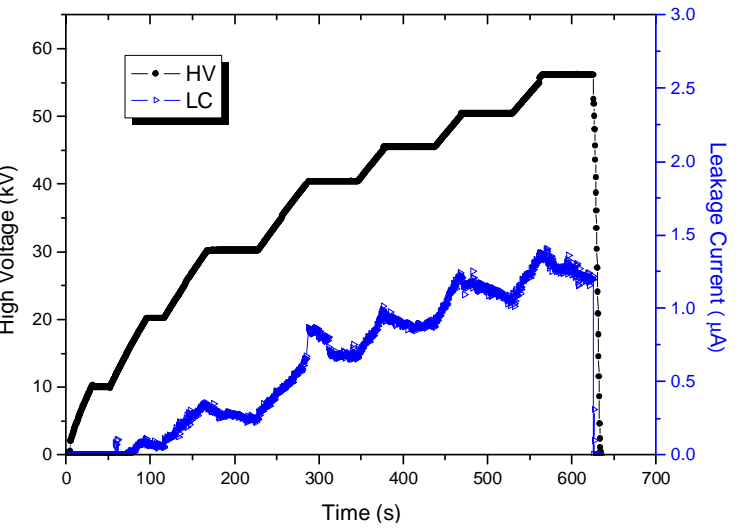

Fig.6 leakage current test cures 


\section{Conclusion}

Adhesive joints of axial insulation break was studied in detail, including stainless steel electrodes and insulating structure. Wet winding process was chosen for Glass Fiber Reinforced Plastic, inner insulation tube, and threaded adhesive method was chosen for joints bonding GRP to Stainless Steel. It is fairly good results to eliminate the interface crack in low temperature heat shrinkage and mechanical stress to meet requirements for superconducting magnetic systems.

\section{Acknowledgements}

The research work was supported by National Natural Science Foundation of China under Grant No. 51667009.

\section{References}

[1] Yang Changchun Pan Wanjiang. Design and analysis on ITER axial insulation breaks. Nuclear Fusion and Plasma Physics, 30(3), pp.272-276, 2010.

[2] Yang Changchun. Experiment research on low-temperature mechanic fatigue performance of ITER axial insulation breaks. Cryogenic \& Superconductivity, 39(11), pp.7-10, 2011.

[3] Yu X., Wu, W. Pan, W., Han S., Wang L., Wei, J. Liu L.; Du S., Zhou Z. Foussat, A.; Libeyre, P., Development of Insulation Technology with Vacuum-Pressure-Impregnation (VPI) for ITER Correction Coil. IEEE Transactions on Applied Superconductivity, 22 (3), pp. 212-206, 2012.

[4] Zhang Yuanbin, Pan Wanjiang. Theoretical and experimental analysis of cryogenic mechanics property for EAST Tokamak composite insulators [J]. Atomic Energy Science and Technology, 41(6), pp.752-755, 2007.

[5] BAUER K, FINK S.The electrical insulation system of a forced flow cooled superconducting (SC) magnet[J]. Cryogenics, 38 pp.1 123-1 134, 1998 